\title{
24 \\ INFORMATION SYSTEMS INNOVATION RESEARCH AND THE CASE OF RFID
}

\author{
Ann Brown \\ Cass Business School, City University \\ London, United Kingdom \\ Anjali Bakhru \\ Open University Business School \\ Milton Keynes, United Kingdom
}

\begin{abstract}
Radio frequency identification (RFID) is a complex ICT application. Adoption by organizations has been relatively slow. This paper assesses the contribution that research into information systems adoption and diffusion can make to understanding and predicting the diffusion of RFID. The paper concludes that traditional research methods are inappropriate for such applications. Information systems stage research and diffusion research offer more promising models.
\end{abstract}

Keywords Radio frequency identification, RFID, technology adoption, technology diffusion, process research

\section{INTRODUCTION}

Radio frequency identification (RFID) is not a new technology. Example applications date as far back as the 1950s (Twist 2005). Interest in this technology began to accelerate during the late 1990 s mainly as a consequence of the high rate of development in the various constituent technologies that combine to create one type of RFID application. An RFID system is a combination of several technologies: wireless communications, computer hardware, electronic storage, and software programs. These elements operate

Please use the following format when citing this chapter.

Brown, A, and Bakhru, A., 2007, in IFIP International Federation for Information Processing, Volume 235, Organizational Dynamics of Technology-Based Innovation: Diversifying the Research Agenda, eds. McMaster, T., Wastell, D., Ferneley, E., and DeGross, J. (Boston: Springer), pp. 363-376. 
together to capture and process data on individual items and their movements by an electronic tagging system. The system collects real-time information on mobile items (people or products or assets) for storage and subsequent analysis by computer. It is already clear that its potential application is to a variety of uses across different sectors. RFID has been called a revolutionizing technology with multiple uses and potential applications. Nonetheless it has been characterized by a relatively slow rate of adoption (Angeles 2005; Reiner and Sullivan 2005; Saunders 2005).

There is a considerable body of work into information systems innovation research. This has led to a number of theories on information technology adoption and diffusion. What do these theories suggest about RFID? What help does this work provide in explaining and forecasting the progress of RFID adoption? This paper aims to assess the contribution of IS innovation research in understanding the progress of RFID adoption and diffusion.

This paper starts with a description of the characteristics of the RFID technology. The following three sections apply the work carried out by IS researchers into IT innovation to RFID technology within the three approaches: traditional IT adoption research, process modeling, and diffusion studies.

\section{CURRENT STATE OF RADIO FREQUENCY IDENTIFICATION (RFID) TECHNOLOGY}

The business potential of RFID is not seriously questioned. The collection and analysis of real-time information on mobile items (people, products, or assets) has many obvious applications that seem certain to yield significant business value in terms of cost savings and enhanced service levels.

The most widely discussed applications are those dealing with the supply chain and retail business (Angeles 2005; Kopalchick and Monk 2005; Twist 2005; Wilding and Delgado 2004b). The application developed by Scottish Courage, a brewer in the United Kingdom, demonstrates the value of this type of application (Wilding and Delgado 2004a). RFID keeps track of mobile items. The company has used RFID technology for managing the movement of the barrels in which it delivers the beer to its customers. The technology offers a way to attach a label (tag) to any physical item containing unique information about that item (in this case, the barrel). This can then be read by or in some cases updated by a receiver (reader) placed at some distance from the tag. Wireless technology is used to achieve communication between tag and reader, when the tag is not in view. The data on every tagged item in the system can be fed in real time from this network of readers into a computer management system to be processed. The tags provide a unique identification for individual items, providing their location and the option of considerable additional information about the item if required and cost effective. The brewery now knows the location and progress of each of its 1.9 million containers. Information is collected by readers at several stages--at the brewery, upon delivery to the customer, during audits, and following return as an empty. This is a typical example of asset tracking. The benefits flow from the increased visibility of the containers and are predominantly cost saving and service level enhancements. For example, theft, loss, and container cycle time have all been significantly reduced, quality issues solved as a consequence of traceability, and there are fewer errors of distribution. 


\subsection{Rate of Adoption}

It is generally agreed, however, that widespread adoption has been slow (Angeles 2005; Reiner and Sullivan 2005; Saunders 2005). Retailers in the United Kingdom have been investigating the technology for some years. Sainsbury's (the UK supermarket chain), for example, started a pilot study in 2000. Computer Weekly's quarterly online survey of UK IT directors on technology adoption by UK businesses in June 2006 found that only 8 percent of businesses were using it in any guise (including pilot schemes) with a further 11 percent investigating its potential. These figures were virtually unchanged in the September 2006 survey. A similar pattern is reported in the United States. A survey sponsored by NCR Corporation in May 2006 found that adoption rates in the United States were modest and unlikely to change significantly (Kilcourse 2006). The results showed that only 9 percent of retailers had an implementation time line in place and most of these were at the pilot stage. The much higher figure of 44 percent for manufacturers was attributed to the effect of mandates by retail trading partners, of which U.S. retailers Wal-Mart and Target were the most frequently cited partners.

Numerous reports in the press over the last 2 years show the caution with which business is treating this technology. Many retailers, for example, seem aware of the technology (Kilcourse 2006) and have investigated RFID technology (through pilot schemes) but have decided to defer adoption until the technology achieves a higher level of performance and/or becomes cheaper. Neither Sainsbury's (Cray 2005) nor Exel (a logistics company) consider that there is or will be a business case for any application for some years to come (Computer Weekly, February 2005). Estimates for the widespread adoption by companies of RFID applications include 2010 and beyond.

\subsection{RFID Technology Elements}

An RFID system is composed of four main elements, drawing on four types of technologies: the tags, the wireless enabled receiver/transmitter, standards for product codes and tag/reader equipment, and the computer information system that processes the data delivered by the RFID system. These technologies are undergoing continuous development (Angeles 2005; Smith and Konsynski 2003; Twist 2005). Hence, performance in terms of capacity, reliability, accessibility, and costs are constantly changing with consequent effects on total system performance. There are as yet no globally agreed standards. Most readers are compatible with only a single manufacturers tag (Twist 2005). Organizations like GSI UK (headquartered in Brussels, Belgium, and Princeton, New Jersey) are attempting to get corporate support to drive the adoption of global supply chain standards, but have not yet achieved this.

An individual application of RFID can be viewed as one proprietary network based around the system of readers and tags. Tags interact with the network at any point where there is a reader. Information flows from the tag via the reader into the computer system supporting the network. No tags from other networks will be recognized. A network can

'These estimates are from personal communications with Mr. Cray, the IT business partner at Sainsbury's, and from presentations at the GSI UK EPCGlobal Conference in London, June 2005 . 
be for many individual users (for example, the Oyster card system for payment by passengers on the London Underground train system), for one specific application within an organization (for example, Scottish Courage's barrel tracking system), or for an application common to a group of organizations (for example, suppliers to Wal-Mart). These networks require that the class of tagged items all be in the system in order to deliver value. Tracking all but a minority of containers at Scottish Courage, for example, would be of value but the real payoff comes from tracking every container. Hence, the system components can be considered largely infrastructure in that the major investment has to be made for all components of the system up front.

RFID technology has a wide range of potential uses. By 2004, Sainsbury's had identified over 18 separate applications within their operations (Cray 2005). The most promising ones were asset tracking (of trolleys) and employee tracking into and out of company sites (Symmons 2005). Vince Cerf, chairman of Icann (an Internet corporation for assigned names and numbers) and cocreator of the transmission control protocol (TCP), has suggested that the adoption of RFID by groups such as EPCGlobal could "create an internet of things" (Computer Weekly, November 2006a). The parallel with the Internet underlines not only the variety of possible uses for which the technology is already being considered, but raises the possibility of more innovative applications that will only become clear when the technology has reached a higher level of diffusion.

The community interest in and optimism about the future of RFID is large, diverse, and active. The public activity of the relevant community members has been prolonged and intense through conferences (such as the GSI UK EPCGlobal Conference in London in June, 2005), trade press (Computer Weekly and RFID Journal), and academic journal articles (Angeles 2005; Reiner and Sullivan 2005; Saunders 2005; Wilding and Delgado 2004a, 2004b).

Potential or actual applications of RFID include (Smith and Konsynski 2003):

- Item tracking (e.g., inventory, containers, mail parcels, books, people)

- Asset tracking (e.g., railway coaches, supermarket trolleys)

- Identification for Security (e.g., smart cards)

- Item labeling (e.g., information on "sell by" dates or to identify products as genuine)

- Contactless payments (e.g., public transport systems, motor way tolls)

The benefits cited vary according to application and context, and include reduction in accidents or losses, error reduction resulting in increased safety, cost reduction, efficiency gains, fraud prevention, customer service enhancement, and the targeting of recalls.

\subsection{Characterizing RFID Adoption}

From this description it becomes possible to identify those factors in relation to RFID technology that are critical to the business case and adoption decision.

- Cost: installation involves both high up-front and operating costs

- Technical performance: current performance is adequate only for some of the potential applications 
- Interdependence of the operators

- Knowledge base: new knowledge and expertise required for installation and ongoing operational management

- Complexity: wide variety of applications involving differing levels of technical and operational complexity

- User base: large and active community of specialist experts and groups supportive of the application of the technology

For an individual RFID application, there is a very significant infrastructure cost required in installing the whole network of readers, software, and tags. The organizational costs of operational changes may also be substantial. In addition, even moderate applications, such as the Scottish Courage barrel tracking system, generate an enormous amount of extra data that has to be stored electronically, processed quickly, and integrated into other organizational information systems if it is to create value. The Scottish Courage application, for example, required readers at 26 depots and on 600 vehicles generating over $30 \mathrm{~m}$ per keg or barrel of movements annually (Wilding and Delgado 2004a). Storage and computing power and new software have to be installed to meet these additional demands. Operational costs are not insignificant. An unusual facet of an RFID system is the issue of the price of RFID tags relative to the cost of the underlying product to which it is to be attached and to the potential savings. The tags incorporate a chip that stores the data and an antenna that transmits/receives information. Chips can be relatively simple, containing as little as an ID (passive), or highly sophisticated, containing a large amount of information that can be updated at every reader point. Tag costs reflect the degree of sophistication. Chip capacity is rising and costs reducing in line with Moore's law (Moore 2003), but tag costs are still considered far in excess of that required for many applications to be cost effective.

At present, the level of technical performance presents a number of problems. At an interview in August 2005, Sainsbury's IT managers concerned with this technology commented that the wireless communications link can be a weak part of the system (Symmons 2005). In their experience, it failed to reach far and could produce false reads due to local interference from, for example, metallic objects. For Sainsbury's, the reliability of the read/write function was critical to the business case. In their view, error rates were still too high. The survey sponsored by NCR Corporation in May 2006 (Kilcourse 2006) found that companies considered the technical challenges to be significant. These included problems with attaching RFID tags to products, poor read rates, and interference from other wireless devices that are in use in the RFID-enabled facility.

RFID applications deliver value from the performance of the system as a whole. All facets of the system are highly interdependent. Hence the work of all operational staff is also highly interdependent. If one operator makes a mistake, the performance of the whole suffers.

To develop a new application of RFID, an organization requires specialist expertise for both the installation of the new technology and its effective operation. The lack of agreed technical standards exacerbates the complexities inherent in installation and implementation of new systems. The concern with the complexities of implementation is manifest in the many long running pilot projects of RFID supply chain applications that have been reported in the trade press. Marks \& Spencer (a UK clothes retailer), for 
example, have been running pilots since 2003 (Collins 2004, 2005; Marks \& Spencer 2003,2005 ) and announced their move to a full system in late 2006 (Computer Weekly, November 2006b). Sainsbury's considered RFID as early as 2000. Rolls-Royce (a UK defense equipment manufacturer) started planning for the use of RFID in 2004 mainly to meet the demands of the U.S. Department of Defense for RFID compliant supply chain by 2007 (Computer Weekly, October 2006). The company was still in the trial stage at November 2006.

Complexity of installation varies between applications. For example, supply chain applications, such as those announced by Wal-mart and Marks \& Spencer, involve many organizations, which increases the problems of implementation. However, this use of RFID for this type of application is simple in concept, being in effect a replacement for bar code technology, and at present appears to create little organizational change. For other types of RFID applications, such as asset management and contactless payments the implementation stages could be less complex.

\section{TRADITIONAL IS ADOPTION RESEARCH AND RFID}

Traditional approaches to IS adoption research are concerned with understanding the drivers of adoption of information and communication technology applications within target populations of individual users or organizations (Fichman 2004; Gallivan 2001; Jeyjaraj et al. 2006). The research question is, "What factors facilitate or hinder adoption and diffusion of IT-based innovation within a population of potential adopters?" (Fichman 2004). The goal of IT innovation research has, therefore, been to provide advice to managers on how to gain acceptance of new information technology investment at either the personal level of the user or at the organizational level of new project investment. The primary aim of this research is the development of models that represent as closely as possible the adoption process itself rather than models that focus on the deployment of specific ICT applications.

The research approach has been to model the adopter process of individuals and organizations based on a core set of theories and frameworks that seek to explain their behavior (Gallivan 2001). Jeyjaraj et al. (2006) carried out a review of empirical work in this tradition published in the main IS journals between 1992 and 2003 . Their results confirmed Gallivan's (2001) view that the work tended to draw on a core set of theoretical frameworks. Of these Rogers' (2003) innovation diffusion theory (IDT) was one of the few to be applied at both the individual and the organizational level (Jeyjaraj et al. 2006). The technology adoption model (TAM) developed by Davis (1989) and based on the theory of reasoned action (Fishbein and Ajzen 1975) and its variants, is probably the most widely applied model at the individual user level.

The dominant paradigm is positivist and works on the assumption that the more organizations and individuals possess of the right characteristics, the more likely is it that the IT innovation will be adopted. Fichman (2004, p. 315$)$ expresses this as follows:

This paradigm is typified by the desire to explain innovation using economicrationalistic models, whereby organizations that have a greater quantity of what might be called the "the Right Stuff" (i.e., greater innovation-related needs and 
abilities) are expected to exhibit a greater quantity of innovation (i.e., greater frequency, earliness or extent of adoption).

Models are usually quantitative and seek to predict the value of such quantities as perceived system use, intention to use, rate of adoption, and actual system use (Jeyaraj et al. 2006). These become the dependent variables used as surrogates for quantity of innovation.

Theory has proposed a wide range of factors that could influence adoption (the independent variables). Jeyaraj et al. (2006) categorize these into four groups: environmental descriptors, organizational characteristics, individual (variables describing individual user characteristics), and innovation, which deals with the technology characteristics. Hence these models tend to focus on the characteristics of the adopters, whether these are individuals or organizations. The (innovation) variables describing the technology application are generic and focus on the general benefits that the ICT application might bring, rather than a specific description of what the ICT application will do. For example, TAM includes the subjective measures of perceived usefulness, while IDT incorporates that of perceived competitive advantage. This is not an approach that could incorporate the unique characteristics of an application like RFID.

Empirical work establishes numerical measures of these quantities and tests the model for predictive power, with data collected for individual ICT applications at a specific time and context (Chau and Tam 1997; Cho 2006; Fang et al. 2005; Mun et al. 2006; Venkatesh and Davis 2000). The research based on the technology adoption model is typical of this type of research. It was originally developed with the aim of creating a model to predict and explain user adoption of individual applications in the workplace. The standard methodology for the empirical work in TAM studies is to set up a study that seeks to explain "a specific behavior (usage) toward a specific target [IS application] within a specific context [organizational situation]" (Davis et al. 1989). Typically users are introduced or trained to use a new IS application and then a questionnaire is administered to find out their intentions for adoption (Cho 2006; Fang et al. 2005; Mun et al. 2006; Venkatesh and Davis 2000). Many of the variables, both independent and dependent, tested in this way are constructs largely based on self assessment. The model is measured by how much variance in intentions it explains. Most organizational studies take the same approach with different choices of independent variables (Chau and Tam 1997). Others use case material but have similar goals, namely the identification of the factors that lead individual organizations to adopt specific applications. Each study produces results for one type of IS application for one situation (organization, business unit, work group). More recent research has attempted to improve the performance of these types of models through adding variables or creating composites of previous work (Gallivan 2001; Venkatesh and Davis 2000; Venkatesh et al. 2003). Venkatesh et al. (2003), for example, created the unified theory of acceptance and use of technology (UTAUT) to predict individual user response to new technology drawing on eight existing models (including TAM) in common use. Their empirical work tested this model and found that it gave a higher explanatory power than each of the eight individual models.

Like all modeling activity, this is a simplification of what actually happens. There are a number of concerns with this approach. Theoretical problems include the proinnovation bias (Fichman 2004; Jeyjaraj et al. 2006) resulting from the fundamental 
assumption that technology adoption is beneficial. The reliance on self assessment introduces recall bias, in which respondents misrepresent or have forgotten their behavior (Jeyjaraj et al, 2006; Szajina 1996). The reliance on rational decision making does not fit the experience of many researchers (Nutt 2002). Use of survey data is a poor way to capture behavior changes over time. The assumption of voluntary adoption decisions does not match many situations where adoption is mandated. Nonetheless there is substantial agreement that this approach has achieved some success (Fichman 2004; Gallivan 2001; Jeyjaraj et al. 2006). The models developed within the dominant paradigm have proved stable with good predictive ability for some circumstances. This poses the question: for what conditions and questions do these models work adequately?

Gallivan's (2001) review of the performance of traditional adoption research frameworks established that studies that showed strong explanatory power were those in which individual users voluntarily decide whether to use personal tools such as word processing, which also do not require extensive specialized knowledge (Cell 1 in Table 1). In his classification matrix, based on Fichman (1992), traditional adoption models have achieved less success in situations where adoption is mandated by the organization (Table 1, Cell 2) and situations where either there is a high level of user interdependence or the application requires considerable effort to learn to use it (Table 1, Cell 3). But traditional models fit least well for situations in which the ICT application is complex, requires a high level of coordination across users and departments, and is mandated by the organization (Table 1, Cell 4).

As the previous section established, RFID has both characteristics of high user interdependency and a high knowledge burden and hence falls into Cell 4 . Traditional adoption models are likely to prove a poor guide to organizational adoption decisions with respect to RFID. Moreover the pro-technology bias of traditional methods is inappropriate for RFID for which, currently, the cost and performance factors present significant barriers to adoption.

\section{Table 1. Classification Matrix for Traditional Innovation Adoption Research (adapted from Fichman 1992)}

\begin{tabular}{|c|c|c|c|}
\hline & \multicolumn{2}{|c|}{ Locus of Innovation Adoption } \\
\hline & & Individual User & Organization \\
\hline \multirow{2}{*}{ 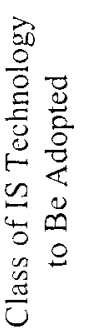 } & $\begin{array}{l}\text { Type 1: Low user } \\
\text { interdependencies } \\
\text { and low knowledge } \\
\text { burden }\end{array}$ & $\begin{array}{l}\text { Cell 1: Traditional } \\
\text { adoption }\end{array}$ & $\begin{array}{l}\text { Cell 2: Organizational } \\
\text { mandate }\end{array}$ \\
\hline & $\begin{array}{l}\text { Type 2: High user } \\
\text { interdependencies or } \\
\text { high knowledge } \\
\text { burden }\end{array}$ & $\begin{array}{l}\text { Cell 3: Knowledge } \\
\text { burden }\end{array}$ & $\begin{array}{l}\text { Cell 4: Organizational } \\
\text { mandate and } \\
\text { knowledge burden }\end{array}$ \\
\hline
\end{tabular}




\section{PROCESS MODELING AND RFID}

Traditional IT adoption research takes a mechanistic view of organizations. This worldview hypothesizes a series of factors that directly drive the adoption decision. It makes the assumption that each factor is an independent variable and does not take account of any interactions between them. It conceptualizes adoption as determined at one point in time, ignoring the dynamic nature of an information systems project and the effect of changing conditions. The measures of adoption tell us little about the final business value achieved. For Cell 4 type ICT applications, the decision to purchase is but the start of a potentially lengthy process of installation and implementation. Implementation of new, complex technology is not a routine operation. Examples abound of IS applications that have been bought by organizations but never deployed (Attewell 1992). It is this process of implementation that determines whether the application is ever fully adopted and the level of business value achieved through its deployment.

Process models offer a way to understand organizational implementation (Gallivan 2001; Soh and Markus 1995). They focus on the sequence of events over time, which appear to lead to an outcome and seek to explain how and why an individual information systems outcome has occurred (Newman and Robey 1992). For process models, factors or categories may or may not help to produce the outcome. Outcomes are not dependent variables but "the 'final cause' of preceding events" (Newman and Robey 1992, p. 251). Stage research models seek to represent this time-related behavior and their relevance to innovation research has been noted by many (Rogers 2003; Tornatzky and Fleischer 1990).

According to Tornatzky and Fleischer (1990), adoption proceeds through a number of stages with successful implementation signaled when it has achieved widespread deployment and complete exploitation for business value. The process of technological innovation is "neither a single event nor even a small number of discrete events" (Tornatzky and Fleischer 1990, p. 27). Individuals and organizations may revisit some stages many times before the new technology reaches total acceptance.

Rogers' (2003) five stage model of adoption and implementation was an early attempt at representing the innovation process in organizations. Although the decision to purchase (Rogers' Stage 3) is an important turning point, adoption cannot be said to have taken place until implementation has been achieved, at least to the extent that some employees make use of the applications on some level. Cooper and Zmud (1990) adapted this to a six-stage model for IS applications. For this line of research, user adoption is of less interest than the extent to which the application is used. This is a combination of breadth of impact and the extent to which the application is assimilated by the organization. Breadth of impact is measured by the number of workgroups, departments, and/or individuals that adopt it (Gallivan 2001). Depth of impact is a more intangible concept. It encompasses the degree to which the application reaches into and changes existing processes and organizational routines (Gallivan 2001; Swanson and Ramiller 1997). Complete assimilation has occurred when routinization (Tornatsky and Fleischer 1990), or confirmation (Rogers' Stage 5) or infusion (Cooper and Zmud's Stage 6) is reached. The potential value of the new application can be thought to lie on a continuum (stretching from negative, if unsuccessful, to positive, when fully assimilated). Both success and business value will be affected by the scale of change required in 
organizational routines and retraining requirements for members of staff. For this approach, adoption is not an automatic benefit (as it is for traditional methods).

This approach gives a description of RFID technology that fits the current situation more closely than the traditional theory. The characteristics of knowledge burden and range of applications with differing levels of complexity noted in section 2 underline the significance of the implementation stage for this technology. Moreover, individual RFID applications require substantial investment for the infrastructure (i.e., at Stage 3 purchase) and may take years to install. Rogers' stage model captures these characteristics. However, process theory offers little practical direction for research design or research method. It is a relatively high-level theory that can be applied in many ways.

For example, Gallivan uses this theory when he creates a three-stage model representing innovation, adoption, and implementation and applies this framework to two case examples. The aim of the empirical research is to capture insights into the implementation process. A case-based approach is used to investigate the views of the key stakeholders. The model is complex and the empirical work time consuming. The results support other work into implementation but are not linked to the special characteristics of the ICT application being studied. The aim is similar to traditional IT adoption research in that it seeks to identify those generic factors that affect adoption and assimilation, so as to be in a position to offer advice on how to support and ensure adoption. It could be considered an extension of traditional studies in that it widens the analysis to include the important stage of implementation.

There is less empirical research in the process or stage modeling tradition and the reason for this is simple. Models can span a wide range of factors, are complex, difficult to apply, and tend to produce results that are difficult to interpret.

\section{IS DIFFUSION RESEARCH AND RFID}

Traditional diffusion theories model how innovations spread both within and between organizations (Rogers 2003; Tornatzky and Fleischer 1990). Diffusion represents a series of individual adoption decisions. Traditional theories assume an equal opportunity to adopt provided there is a demand, that the rate of diffusion depends on the effectiveness of communication between suppliers and potential adopters. It emphasizes the role of signaling, that is, spreading the word about the existence and potential benefits of a new innovation (Attewell 1992). It assumes that institutional factors of either supplier or adopter are not significant in the adoption decision and that the adoption decision is made by an individual using rational decision criteria. There is an implicit assumption that if there is a good case for adoption for one user, then this applies to the rest of the target population of adopters.

Less attention has been paid to diffusion in the IS literature. IS researchers, such as Swanson and Ramiller (1997) and Attewell (1992), who have worked on the subject of the diffusion of IS applications have all argued that many IS applications diverge from the characteristics assumed of innovations for traditional theories like Rogers'. For Cell 4 ICT applications and RFID in particular, these assumptions do not hold. For most RFID applications, many individuals will be involved in the decision. Implementation will involve gaining new technical knowledge. This requires more than knowledge 
transfer. According to Attewell (1992, p. 6), "implementing a complex new technology requires both individual and organizational learning." Complex technologies interact with existing systems in multifaceted ways and organizations master them through using them, not via knowledge transfer. Attewell suggests that the rate of diffusion will accelerate when mechanisms exist to support this learning process. He proposes a knowledge barrier theory of diffusion for complex ICT, in which it is the progressive lowering of know-how barriers that determines the rate of diffusion, not the development of communication channels. Case examples on the spread of computing through the two decades illustrated how the decision varies between organizations depending on their circumstances.

Swanson and Ramiller agree with Attewell as to the significance of the learning requirements for complex ICT applications. However, for them, it is the uncertainty surrounding new ICT that differentiates it most sharply from the traditional description of innovations. "New technology often arrives on the market in an immature state, puzzling as to its benefits, future prospects and long term form" (Swanson and Ramiller 1997, p. 459). They propose an alternative model of the diffusion process for applications like RFID. They suggest that the key factor is the ongoing perceptions and beliefs of the community with material interests in the new IS application which determines the rate of diffusion. This community is made up of those IS practitioners that become knowledgeable about the new technology, the business managers for which the new technology may be of value, consulting firms, academic researchers, user groups, industry pundits, technology vendors, and conference organizers (both academic and trade). These groups create the current dominant view (organizing vision) of how and where the technology can be used, its potential business value, and, most significantly, support the learning process that potential adopter organizations must go through. The vitality and level of public activity of this heterogeneous group offers a guide to the current state of the innovation. The community's discourse is carried out via such outlets as conferences, trade publications, journal papers, consultant's offerings, the business press, and exemplar cases of adoption. A high level of very visible activity creates the conditions for diffusion.

This theory of diffusion focuses on the individual technology and its characteristics. According to this view, an effective description of technology diffusion would require a model specific to the technology. Such a model would incorporate such factors as the business case, implementation issues, risks, and community beliefs and attitudes.

As noted in section 2, RFID technology conforms to this description. The business case is still uncertain for many applications and it carries a high knowledge burden. Nonetheless, the organizing vision currently being generated by the interested parties is dense and optimistic. Further work using this theory would require the development of a framework that would describe the factors specific to RFID technology that might affect the organizational adoption decision.

\section{CONCLUSION}

Adoption and diffusion of complex ICTs such as RFID are far from simple processes. This paper has emphasized that traditional research methods are unlikely to build useful 
models of this behavior given their inability to capture the complexity involved. Alternative research approaches are, however, likely to be more promising. Both IS process research (stage models) and IS diffusion research have identified significant factors that are likely to affect the rate of adoption and diffusion of these complex types of ICT. The research issue shifts toward choosing applications that will yield business value and, at the same time, achieve successful implementation. Central to understanding this potential, however, is an appreciation that increasing rates of adoption and diffusion of RFID technology are likely to depend on factors external to the firm. While adoption decisions traditionally take place in relative isolation within an organization's boundaries, adoption decisions regarding RFID will be affected by the decisions of others. The rate of diffusion will ultimately depend not only on the characteristics of the technology but also on the larger community of actors interested in or knowledgeable about the application.

\section{References}

Angeles, R. "RFID Technologies: Supply-Chain Applications and Implementation Issues," Information Systems Management (22:1), Winter 2005, pp. 51-65.

Attewell, P. "Technology Diffusion and Organizational Learning: The Case of Business Computing," Organizational Science (3:1), 1992, pp. 1-19.

Chau, P., and Tam, K. Y. "Factors Affecting the Adoption of Open Systems: An Exploratory Study," MIS Quarterly (21:1), March 1997, pp. 1-26.

Cho, V. "A Study of the Roles of Trusts and Risks in Information-Oriented Online Legal Services Using an Integrated Model," Information and Management (43:4), January 2006, pp. 502-520.

Collins, J. "Marks \& Spencer Expands RFID Trial," RFID Journal, February 20, 2004 (available online at http://www.rfidjournal.com/article/articleview/791/1/1/).

Collins, J. "Marks \& Spencer to Extend Trial to 53 Stores," RFID Journal, February 18, 2005 (available online at http://www.rfidjournal.com/article/articleview/1412/1/1/).

Computer Weekly. "Computer Weekly CIO Index: Technology Adoption," June 2006, p. 12.

Computer Weekly. "Computer Weekly CIO Index: Technology Adoption," September 2006, p. p. 14.

Computer Weekly. "Logistics Firms Hold Back but Are Key to Wide Scale RFID Roll-Out," February 2005, p. 10.

Computer Weekly. "Rolls-Royce Fires Up RFID Trail to Meet US Army Supply Chain Orders," October 2006, p. 14.

Computer Weekly. "The End of the Web as We Know It," November 2006a, p. 24.

Computer Weekly. "M\&S Ready to Start National Roll-Out of Item-Level RFID," November 2006 b, p. 5.

Cooper, R. B., and Zmud, R. W. "Information Technology Implementation Research: A Technological Diffusion Approach," Management Science (36), a1990, pp. 123-139.

Cray, T. IT Business Partner, Sainsbury's. Personal communication, 2005.

Davis, F. "Perceived Usefulness, Perceived Ease of Use Interface, and User Acceptance of Information Technology," MIS Quarterly (13:3), September 1989, pp. 319-340.

Davis, F., Bagozzi, R., and Warshaw, P. "User Acceptance of Computer Technology: A Comparison of Two Theoretical Models," Management Science (35:8), 1989, pp. 982-1003.

Fang, X., Chan, S., Brezezinski, J., and Xu, S. "Moderating Effects of Task Type on Wireless Technology Acceptance," Journal of Management Information systems (22:3), 2005, pp. 123-157. 
Fichman, R. "Going Beyond the Dominant Paradigm for Information Technology Innovation Research: Emerging Concepts and Methods," Journal of the Association for Information Systems (5:8), 2004, pp. 314-355.

Fichman, R. "Information Technology Diffusion: A Review of Empirical Research," in J. I. DeGross, J. D. Becker, and J. J. Elam (eds.), Proceedings of the $13^{\text {th }}$ International Conference on Information Systems, Dallas, TX, 1992, pp. 195-206.

Fishbein, M., and Ajzen, J. Belief, Attitude, Intention and Behavior: An Introduction to Theory and Research, Reading, MA: Addison-Wesley, 1975.

Gallivan, M. "Organizational Adoption and Assimilation of Complex Technological Innovations: Development and Application of New Framework," The DATABASE for Advances in Information Systems (32:3), 2001, pp. 51-85.

Jeyaraj, A., Rottman, R., and Lacity, M. "A Review of the Predictors, Linkages and Biases in IT Innovation Adoption Research," Journal of Information Technology (21:1), 2006, pp. 1-23.

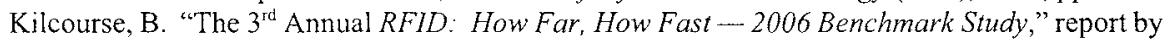
Retail Systems Alert Group, sponsored by NCR Corporation, May 2006 (downloaded from NCR's website in November 2006).

Kopalchick III, J., and Monk, C. "RFID Risk Management," Internal Auditor (62:2), 2005, pp. 66-72.

Marks \& Spencer. "Marks \& Spencer Develops Intelligent Clothing," Press Release, Apri1 7, 2003 (available online at http://www2.marksandspencer.com/thecompany/mediacentre/ pressreleases/2003/com2003-04-07-00.shtml).

Marks \& Spencer. "Background to Marks \& Spencer's Business Trial of RFID in its Clothing Supply Chain," Press Release, February 18, 2003 (available online at http:/www2. marksandspencer.com/thecompany/mediacentre/pressreleases/2005/com2005-02-18$00 . \operatorname{shtml})$.

Moore, G. "No Exponential Is Forever...But We Can Delay Forever," presentation to 2003 IEEE International Solid-State Circuits Conference, February 2003 (available online at at http://www.intel.com/research/silicon/mooreslaw.htm).

Mun, Y. Y., Jackson, J., Park, J., and Probst, J. "Understanding Information Technology Acceptance by Individual Professionals: Towards an Integrative View," Information and Management (43:3), 2006, pp. 350-363.

Newman, M., and Robey, D. "A Social Process Model of User-Analyst Relationships," MIS Quarterly (19:2), June 1992, pp. 249-266.

Nutt, P. Why Decisions Fail, San Francisco: Berrett-Koehler Publishers Inc., 2002.

Reiner, J., and Sullivan, M. "RFID in Healthcare: A Panacea for the Regulations and Issues Affecting the Industry?," HealthCare Purchasing News Online, June 2005 (available online through http://www.hpnonline.com/).

Rogers, E. Diffusion of Innovations ( $5^{\text {th }}$ ed.), New York: The Free Press, 2003.

Saunders, A. "Can Smart Tags Deliver?," Management Today, February 9, 2005, pp. 50-53 (available online at http://www.clickmt.com/public/news/index.cfm? fuseaction=fulldetails\&newsUID=467e3a73-9051-41e6-a38d-015f67cffb08).

Smith, H., and Konsynski, B. "Developments in Practice X: Radio Frequency Identification (RFID)--An Internet for Physical Objects," Communications of the Association for Information Systems (12), 2003, pp. 301-311.

Soh, C., and Markus, L. "How IT Creates Business Value: A Process Theory Synthesis," in J. I. DeGrosss G. Ariav, C. M. Beath, R. Hoyer, and C. Kemerer (eds.), Proceedings of the $16^{\text {th }}$ International Conference of Information Sysiems, Amsterdam, 1995, pp. 29-41.

Swanson, B., and Ramiller, N. "The Organizing Vision in Information systems Innovation," Organization Science (8:5), 1997, pp. 458-474.

Symmons, N. IT Partner, Supply Chain Management, Sainsbury's. Personal communication, 2005. 
Szajina, B. "Empirical Evaluation of the Revised Technology Acceptance Model," Management Science (42:1), 1996, pp. 85-92.

Tornatzky, L. G., and Fleischer, M. The Processes of Technological Innovation, Lexington, MA: Lexington Books, 1990.

Twist, D. "The Impact of Radio Frequency Identification on Supply Chain Facilities," Journal of Facilities Management (3:3), 2005, pp. 226-239.

Venkatesh, V., and Davis, F. "A Theoretical Extension of the Technology Acceptance Model: Four Longitudinal Field Studies," Management Science (46:2), 2000, pp. 186-204.

Venkatesh, V., Morris, M., Davis, G., and Davis, F. "User Acceptance of Information Technology: Towards a Unified View," MIS Quarterly (27:3), September 2003, pp. 425-478.

Wilding, R., and Delgado, T. "RFID Demystified: Supply-Chain Applications," Logistics \& Transport Focus (6:4), May 2004a, pp. 42-48.

Wilding, R., and Delgado, T. "The Story So Far: RFID Demystified," Logistics \& Transport Focus (6:3), April 2004b, pp. 26-31.

\section{About the Authors}

Ann Brown is a senior lecturer in Information Management at Cass Business School, City University. Her research is on information systems in organizations, with a special focus on the problem of obtaining business value from information and communications technology. Ann can be reached by e-mail at a.p.brown@city.ac.uk.

Anjali Bakhru is a lecturer in Strategic Management at the Open University Business School in the United Kingdom. Her research encompasses resource-based evolutionary approaches to competitive advantage, and she has undertaken research on the challenges of new market entry with respect to on-line markets. Anjali can be reached by e-mail at a.bakhru@open.ac.uk. 